\title{
Comparison of wood volume estimates of young trees from terrestrial laser scan data
}

\author{
Matthias Kunz(1), \\ Carsten Hess ${ }^{(2)}$, \\ Pasi Raumonen (3), \\ Anne Bienert ${ }^{(4)}$, \\ Jan Hackenberg ${ }^{(5)}$, \\ Hans-Gerd Maas ${ }^{(4)}$, \\ Werner Härdtle ${ }^{(2)}$, \\ Andreas Fichtner ${ }^{(2)}$ \\ Goddert Von Oheimb ${ }^{(1)}$
}

\begin{abstract}
Many analyses in ecology and forestry require wood volume estimates of trees. However, non-destructive measurements are not straightforward because trees are differing in their three-dimensional structures and shapes. In this paper we compared three methods (one voxel-based and two cylinder-based methods) for wood volume calculation of trees from point clouds obtained by terrestrial laser scanning. We analysed a total of 24 young trees, composed of four different species ranging between $1.79 \mathrm{~m}$ to $7.96 \mathrm{~m}$ in height, comparing the derived volume estimates from the point clouds with xylometric reference volumes for each tree. We found that both voxel- and cylinder-based approaches are able to compute wood volumes with an average accuracy above $90 \%$ when compared to reference volumes. The best results were achieved with the voxel-based method $\left(r^{2}=0.98\right)$. Cylinder-model based methods $\left(r^{2}=\right.$ 0.90 and 0.92 respectively) did perform slightly less well but offer valuable additional opportunities to analyse structural parameters for each tree. We found that the error of volume estimates from point clouds are strongly species-specific. Therefore, species-specific parameter sets for point-cloud based wood volume estimation methods are required for more robust estimates across a number of tree species.
\end{abstract}

Keywords: Mixed Forests, Quantitative Structure Models, Voxel-based, Xylometry rived from measurements of the diameter at breast height (DBH) and tree height (TH - Picard et al. 2012) coupled with harvesting and weighing of the observed trees. In monocultures with well studied species those allometric estimates can perform well (Muukkonen 2007), especially in mature stands. However, allometric equations that were developed in pure stands are less reliable in mixed forest stands with different tree ages and more complex structures. In such cases the exact equations may simply be unknown, and using mean allometric equations may be too vague or even misleading (Nölke et al. 2014, Forrester \& Pretzsch 2015). In addition, many
(1) Institute of General Ecology and Environmental Protection, Technische Universität Dresden, PF 1117, 01735 Tharandt (Germany); (2) Faculty of Sustainability, Institute of Ecology, Leuphana University Lüneburg, Scharnhorststr. 1, Lüneburg 21335 (Germany); (3) Department of Mathematics, Tampere University of Technology, PO Box 553, 33101 Tampere (Finland); (4) Institute of Photogrammetry and Remote Sensing, Technische Universität Dresden, 01062 Dresden (Germany); (5) INRA, Centre de Nancy, Biogéochimie des Ecosystèmes Forestiers, Champenoux (France)

@ Matthias Kunz (matthias.kunz@tu-dresden.de)

Received: Jun 27, 2016 - Accepted: Feb 16, 2017

Citation: Kunz M, Hess C, Raumonen P, Bienert A, Hackenberg J, Maas H-G, Härdtle W, Fichtner A, Von Oheimb G (2017). Comparison of wood volume estimates of young trees from terrestrial laser scan data. iForest 10: 451-458. - doi: 10.3832/ifor2151-010 [online 2017-0404]

Communicated by: Luca Salvati studies deal with large sample sizes which adds further complexity and variation. Therefore, efficient methods for measuring biomass for a large number of trees are desired.

To overcome these challenges airborne or spaceborne remote sensing approaches are typically used to estimate biomass on a global or regional scale (Hese et al. 2005). For small scale applications, up to the plot or individual-tree level, terrestrial techniques are preferable as they allow to measure within the stand. To avoid destructive approaches to get values for wood volume, and ultimately biomass, terrestrial laser scanning (TLS) can be applied. TLS (also referred to as terrestrial lidar) is a well established non-destructive surveying technique that allows to capture fully three-dimensional (3-D) point clouds representing trees (Henning \& Radtke 2006) with a high precision and spatial resolution. Photogrammetric approaches, e.g., handheld or UAV-based digital camera systems in combination with multi-image matching techniques, may also be used to derive such point clouds as a lower cost alternative (Mikita et al. 2016). 3-D cameras (also called range imagers) measuring a distance value for each camera pixel by time-offlight measurement techniques (Oggier et al. 2003) are another alternative for capturing 3-D point clouds. In the near future, the techniques will even be available in smartphones, and solid state lidar devices will depict another option for compact lowcost 3-D point cloud data acquisition. 
Over the past decade a number of methods have been developed to derive common tree inventory parameters, such as $\mathrm{DBH}, \mathrm{TH}$, ground diameter (GD), and crown radii, from TLS point clouds in an automated or semi-automated fashion (Thies et al. 2004, Maas et al. 2008, Seidel et al. 2011a, Li et al. 2014, Seidel et al. 2015). The extraction of wood and crown volumes, as a more complex task, has specifically advanced over recent years (Raumonen et al. 2013, Bienert et al. 2014, Liang et al. 2014, Hackenberg et al. 2015b, Martin-Ducup et al. 2016). However, there are currently no commercially available software packages that deliver wood volumes from TLS point clouds in mixed stands. One reason is that available methods of wood volume calculation from point clouds cannot be applied easily across multiple species and tree sizes. Most methods rely on several input parameters and are still an active field of research. In many cases an advanced knowledge of the respective method is required.

In the literature several methods are described that utilize $3-D$ voxels grids to compute volumes of trees (Gorte \& Pfeifer 2004, Hosoi et al. 2013, Bienert et al. 2014). Although there are methodological differences among them, they are similar in the sense that they mostly need just one input parameter, the voxel size. An advantage of the voxel-based methods is that they can account for real stem shapes with irregularities and thus are not limited to symmetrical shapes (e.g., cylinders), which are used in many geometric-model based approaches (Akerblom et al. 2015). A disadvantage is that heavily occluded branches are often not fully recovered and their volume may be biased.

The other major group of modeling approaches comprises methods which produce quantitative structure models (QSMs). These methods fit geometric primitives into isolated point clouds of trees. The resulting hierarchical collection of cylinders is based on segmentation of the point cloud into individual tree parts (stem and branches). An advantage of these methods is that they can directly deliver the tree topology (branching structure and order) from the local connectivity of the segmentation. Also occlusion is less problematic because the symmetry of the fitted shapes can account for missing points. Reported QSM producing methods, or methods with the capability to produce QSMs within literature can be classified into four different general approaches. A wide range of methods (Xu et al. 2007, Livny et al. 2010, Côté et al. 2011, Delagrange et al. 2014) relies on Dijkstra's Algorithm (Dijkstra 1959) to extract the skeleton of a tree which can serve as a basis for the cylinder fitting. Other tree-skeletonization methods which could replace Dijkstra's algorithm are reported as well (Bucksch \& Lindenbergh 2008, Bucksch et al. 2010, Wang et al. 2014). The second approach relies on segmentation of the point cloud into branches using neighborhood structure of small subsets of the point cloud (Raumonen et al. 2013). Some other methods utilize search spheres recursively to follow the tree architecture from the root of the tree to its tips and connect fitted circles on the sphere-surfaces to cylinders (Jayaratna 2009, Hackenberg et al. 2014, Lamprecht et al. 2015). Lastly one method fits directly ellipses into the cloud by utilizing principal curvature and principal directions of each point (Aiteanu \& Klein 2014).

The motivation of this study was to compare three available methods, one voxelbased and two cylinder-fitting techniques (Raumonen et al. 2013, Bienert et al. 2014, Hackenberg et al. 2014), and to analyze which of these methods are practical and able to compute reliable wood volume estimates across a range of tree species. For this test we quantified and compared volume estimates from TLS-derived point

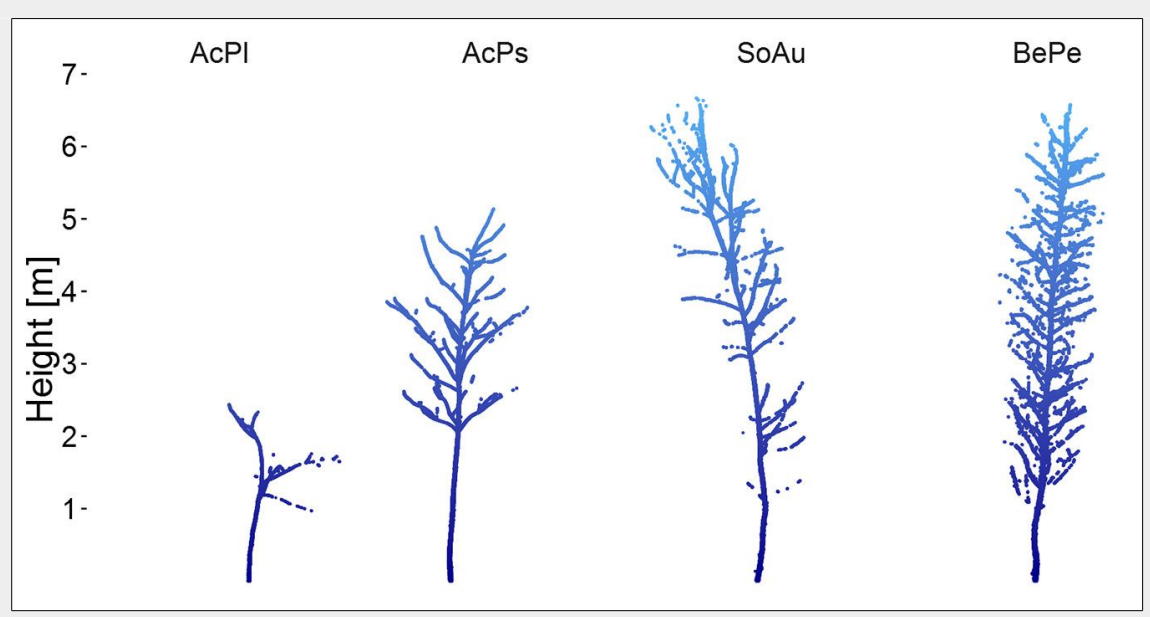

Fig. 1 - Representative sample point clouds of the four species in this study. Species abbreviations refer to Acer platanoides (AcPI, Norway maple), Acer pseudoplatanus (AcPs, Sycamore maple), Sorbus aucuparia (SoAu, Rowan), and Betula pendula (BePe, Silver birch). clouds of young trees of different species. Most of the above TLS-based studies have been shown to deliver acceptable estimates of wood volumes, but so far not many have been tested on the same set of tree samples. We focused on younger trees because they are often missed or underrepresented in the analysis of mixed forest stands (Bayer et al. 2013, Pretzsch 2014), despite their great ecological relevance. As noted by Ashcroft et al. (2014) most studies of trees with TLS are biased towards forestry and less focused on ecological applications. Planted forest biodiversity experiments, e.g., BIOTREE (Scherer-Lorenzen et al. 2007) or BEF-China (Bruelheide et al. 2014), that mainly consist of young trees will also benefit from this study. To validate the estimates we used xylometric measurements of harvested trees.

\section{Material and methods}

\section{Target trees and study sites}

For our analysis we selected data from two different scan campaigns. From Hess et al. (2015) we used point clouds from 18 trees that were scanned and harvested from a forest in Enzen ( $52^{\circ} 19^{\prime} 16^{\prime \prime} \mathrm{N}, 09^{\circ} 09^{\prime}$ $47^{\prime \prime}$ E), Lower Saxony, Germany. In addition, we included point clouds of six trees from Bienert et al. (2014) that were scanned and harvested from a forest in Adendorf ( $\left.53^{\circ} 17^{\prime} 00^{\prime \prime} \mathrm{N}, 10^{\circ} 27^{\prime} 00^{\prime \prime} \mathrm{E}\right)$, Lower Saxony, Germany. In total 24 trees were selected comprising of four species: Acer platanoides L. (AcPl, Norway maple), Acer pseudoplatanus L. (AcPs, Sycamore maple), Sorbus aucuparia L. (SoAu, Rowan), and Betula pendula ROTH (BePe, Silver birch). The trees were selected based on the following criteria: (i) understorey trees that stand in groups; (ii) height between $1.3 \mathrm{~m}$ and $8 \mathrm{~m}$; (iii) different structural habitus and species. Their structural complexity, that is the number, length and middiameter of branches of different branch order and the crown shape, increases in the following order: AcPl $<$ AcPs $<$ SoAu $<$ BePe (Fig. 1). This classification was based on diameter and length differences at the different branch order levels of each species as well as on four simple crown variables measured from the point clouds (for details see Hess et al. 2015). For each tree $\mathrm{DBH}, \mathrm{TH}$, and age data was available from conventional measurements, as well as a xylometric measurement of wood volume (see below) after scanning and cutting. DBH was measured using a diameter tape with $0.1 \mathrm{~cm}$ resolution. TH was measured with measurement tapes as the length of the chopped trunk. Tree age was determined by counting tree rings of a near ground stem disc under a lab microscope. DBH ranged between 1.1-4.5 cm, TH between 1.79-7.96 m, and tree age between 7 and 16 years (see Tab. 1).

We only used data for which comparable information was available and that was acquired in a controlled experimental set- 
Tab. 1 - Characteristics of 24 trees of four species and wood volume estimates (in liter) from point clouds and reference volume from xylometric measurement (Xylo, in liter). Percentage difference for each method from reference volume is given in brackets. Trees are sorted by species and increasing diameter at breast height (DBH). Species abbreviations: (AcPI) Acer platanoides (Norway maple); (AcPs) Acer pseudoplatanus (Sycamore maple); (SoAu) Sorbus aucuparia (Rowan); (BePe) Betula pendula (Silver birch). (TH): tree height; (RMSE): Root Mean Square Error; (MAE): Mean Absolute Error.

\begin{tabular}{|c|c|c|c|c|c|c|c|c|}
\hline \multirow[t]{2}{*}{ Species } & \multirow[t]{2}{*}{ No } & \multirow{2}{*}{$\begin{array}{l}\text { Age } \\
\text { (y) }\end{array}$} & \multirow{2}{*}{$\begin{array}{l}\text { DBH } \\
(\mathrm{cm})\end{array}$} & \multirow{2}{*}{$\begin{array}{l}\text { TH } \\
(\mathrm{m})\end{array}$} & \multirow{2}{*}{$\begin{array}{l}\text { Xylo } \\
\text { (l) }\end{array}$} & $\begin{array}{l}\text { Voxel-based } \\
\text { (Bienert et al.) }\end{array}$ & $\begin{array}{l}\text { Cylinder-based } \\
\text { (Raumonen et al.) }\end{array}$ & $\begin{array}{c}\text { Cylinder-based } \\
\text { (Hackenberg et al.) }\end{array}$ \\
\hline & & & & & & \multicolumn{3}{|c|}{ (l - $\Delta$ to Xylo) } \\
\hline \multirow{6}{*}{ AcPl } & 1 & 7 & 1.1 & 1.79 & 0.283 & $0.312(+10.2 \%)$ & $0.244(-13.8 \%)$ & $0.255(-10.0 \%)$ \\
\hline & 2 & 7 & 1.4 & 2.23 & 0.408 & $0.454(+11.3 \%)$ & $0.347(-14.9 \%)$ & $0.331(-18.9 \%)$ \\
\hline & 3 & 7 & 1.8 & 3.12 & 0.875 & $0.954(+9.0 \%)$ & $0.833(-4.8 \%)$ & $0.808(-7.6 \%)$ \\
\hline & 4 & 7 & 2.0 & 4.88 & 1.335 & $1.520(+13.9 \%)$ & $1.146(-14.2 \%)$ & $1.189(-10.9 \%)$ \\
\hline & 5 & 7 & 2.8 & 4.75 & 2.300 & 3.201 (+39.2\%) & $2.854(+24.1 \%)$ & $2.499(+8.6 \%)$ \\
\hline & 6 & 7 & 4.1 & 3.98 & 3.789 & $4.384(+15.7 \%)$ & $4.430(+16.9 \%)$ & $4.408(+16.3)$ \\
\hline \multirow{6}{*}{ AcPs } & 7 & 16 & 2.5 & 5.52 & 2.324 & $2.422(+4.2 \%)$ & $1.550(-33.3 \%)$ & $1.494(-35.7 \%)$ \\
\hline & 8 & 15 & 2.8 & 5.28 & 2.849 & $2.688(-5.7 \%)$ & $1.734(-39.1 \%)$ & $1.833(-35.6 \%)$ \\
\hline & 9 & 14 & 2.8 & 5.70 & 3.489 & $3.366(-3.5 \%)$ & $2.586(-25.9 \%)$ & $2.473(-29.1 \%)$ \\
\hline & 10 & 16 & 3.0 & 5.93 & 3.459 & $3.239(-6.4 \%)$ & $2.180(-37.0 \%)$ & $2.135(-38.3 \%)$ \\
\hline & 11 & 16 & 3.2 & 6.75 & 3.673 & $3.243(-11.7 \%)$ & $2.308(-37.2 \%)$ & $2.158(-41.3 \%)$ \\
\hline & 12 & 14 & 3.5 & 6.50 & 4.566 & $3.859(-15.5 \%)$ & $2.768(-39.2 \%)$ & $2.486(-45.6 \%)$ \\
\hline \multirow{6}{*}{ SoAu } & 13 & 11 & 2.9 & 7.02 & 3.675 & $3.398(-7.5 \%)$ & $3.724(+1.3 \%)$ & $2.960(-19.5 \%)$ \\
\hline & 14 & 11 & 3.3 & 7.50 & 4.667 & $4.392(-5.9 \%)$ & $5.138(+10.1 \%)$ & $4.436(-6.9 \%)$ \\
\hline & 15 & 12 & 3.9 & 6.27 & 5.260 & $5.108(-2.9 \%)$ & $4.644(-11.7 \%)$ & $4.878(-7.3 \%)$ \\
\hline & 16 & 11 & 4.0 & 6.92 & 6.524 & $5.866(-10.1 \%)$ & $6.256(-4.1 \%)$ & $5.731(-12.2 \%)$ \\
\hline & 17 & 12 & 4.3 & 6.80 & 7.575 & $6.980(-7.9 \%)$ & $6.858(-9.5 \%)$ & $6.498(-14.2 \%)$ \\
\hline & 18 & 12 & 4.5 & 7.96 & 8.522 & $7.769(-8.8 \%)$ & $7.442(-12.7 \%)$ & $6.821(-20.0 \%)$ \\
\hline \multirow{6}{*}{$\mathrm{BePe}$} & 19 & 10 & 2.8 & 6.53 & 3.005 & $2.718(-9.6 \%)$ & $3.280(+9.2 \%)$ & $2.047(-31.9 \%)$ \\
\hline & 20 & 10 & 3.1 & 6.76 & 3.841 & $3.322(-13.5 \%)$ & $5.310(+38.2 \%)$ & $3.064(-20.2 \%)$ \\
\hline & 21 & 10 & 3.5 & 5.76 & 4.742 & $4.938(+4.1 \%)$ & $5.732(+20.8 \%)$ & $4.633(-2.3 \%)$ \\
\hline & 22 & 10 & 3.6 & 6.68 & 5.787 & $5.618(-2.9 \%)$ & 7.066 (+22.1\%) & $6.165(+6.5 \%)$ \\
\hline & 23 & 10 & 4.5 & 7.35 & 8.513 & $7.839(-7.9 \%)$ & $10.060(+18.2 \%)$ & $7.107(-16.5 \%)$ \\
\hline & 24 & 10 & 4.6 & 6.99 & 9.801 & $9.067(-7.5 \%)$ & $10.320(+5.3 \%)$ & $7.618(-22.3 \%)$ \\
\hline Sum $(\mu)$ & - & - & - & - & 101.262 & $96.657(-0.8 \%)$ & $98.811(-5.5 \%)$ & $83.936(-17.3 \%)$ \\
\hline RMSE & - & - & - & - & - & $0.453(12.1 \%)$ & $0.913(22.7 \%)$ & $1.030(23.4 \%)$ \\
\hline MAE & - & - & - & - & - & $0.369(9.8 \%)$ & 0.752 (19.3\%) & $0.818(19.9 \%)$ \\
\hline
\end{tabular}

ting. Although additional TLS-based point cloud data of trees is available online, including larger trees, these data sets are not always sampled with identical methods, e.g., in terms of reference measurements which are partly based on dry weight and not on xylometry analyses. Furthermore, in many cases data on branching structure or species information is missing. Hence, we focused on the analysis of a smaller but comprehensible data set of young trees.

\section{Scan data acquisition, registration and post-processing}

Trees were scanned under leaf-off conditions in May and December 2013, respectively (Bienert et al. 2014, Hess et al. 2015). In order to provide full coverage, all trees were scanned from four different positions, perpendicular to each other, using a FARO Photon $120^{\circledast}$ laser scanner (KorntalMünchingen, Germany), with an angular step size $0.036^{\circ}(2.5 \mathrm{~mm}$ point spacing at 4 $\mathrm{m}$ distance). The distance from each scan position to the trees was between 3-4 $\mathrm{m}$. The instrument height was $130 \mathrm{~cm}$. All scans were performed under clear skies and nearly windless conditions. Four polystyrene spheres $(14.5 \mathrm{~cm}$ diameter) were used as reference targets for co-registration. The resulting point clouds contained $10,000-200,000$ points, depending on the size and complexity of each tree. During the scan process, the built-in FARO LS Clear-Sky and Clear-Contour filters were applied to the captured data. These filters removed incorrect measurements (i.e., when a laser beam was reflected twice), and incorrect sky points. The individual scans for each tree were automatically registered into a local coordinate system with the FARO Scene ${ }^{\circledast}$ software version 5.0.1 (FARO Technologies 2012) using the reference spheres. An overall registration accuracy of $<3 \mathrm{~mm}$ was achieved for the point clouds. Individual trees were extracted manually from the registered point clouds using the software CloudCompare ${ }^{\circledast}$ version 2.54 (EDF 2014). The point clouds of each tree were post-processed by a statistical outlier remover filter plugin ( $\mathrm{qPCL}$ ) within CloudCompare to remove residual noise and ghost points. The tree point clouds in our study do not show heavy shadowing effects as they were scanned from multiple sides under leaf-off conditions. For more details on the scanning and point cloud processing refer to Bienert et al. (2014) and Hess et al. (2015).

\section{Volume estimation}

\section{Reference wood volume measurements}

For the xylometric reference measurements all trunks were cut into segments of
$65 \mathrm{~cm}$ length. Each trunk segment or branch bundle was then fully submerged in a specifically constructed cylindrical water container. The displaced and collected water was weighted and the equivalent water volume was calculated and assigned to each object. The xylometric volumes were determined directly after the scan process so that no reduction in wood volume is expected. The period of submergence of each tree part was short so that the impact of water permeation into the wood was negligible.

\section{Wood volume estimation via voxel space analysis}

For the voxel-based analysis we used the method of Bienert et al. (2014 - updated by Hess et al. 2015, hereafter referred to as Bienert et al.). In a first step, a 3-D voxel space is generated based on the defined voxel size and the dimensions of the input point cloud. In a second step each point of the input cloud is assigned into a voxel based on its location. To remove outliers, e.g., single stray or noise points, a userdefined threshold can be set for the minimum number of points that a voxel must contain in order to be accepted. Here we used a consistent voxel size of $7 \mathrm{~mm}$ and a minimum number of two points per voxel. Smaller $(5 \mathrm{~mm})$ and larger $(10 \mathrm{~mm})$ voxel sizes were tested but did not improve the 
overall estimates. Ideally the chosen voxel size is set to be smaller than the largest stem diameter. If voxel grid downsampling is used, that is, to reduce the number of points of a point cloud to a certain resolution, the voxel size of the volume method is bounded by the chosen voxel grid resolution. To avoid overestimation, which can occur if the voxel size is too large, the voxel volume is adjusted to the point distribution in the $\mathrm{X}$ - and $\mathrm{Y}$-voxel space using axis-parallel bounding boxes (Bienert et al. 2014). For this adjustment the minimum number of two points within a voxel is sensible. After the voxelisation and boundingbox adjustment the algorithm identifies the occluded voxels (i.e., inner and shadowed parts of the stem and branches) by performing a local neighborhood analysis in the $\mathrm{X}$ - and $\mathrm{Y}$-direction in the horizontal layer of each occupied voxel. Using counters occluded voxels are identified and added as tree voxels accordingly. This step is crucial because the volume estimate will be biased when these parts are not accounted for as volume (Gorte \& Pfeifer 2004, Hosoi et al. 2013). In a final step the bounding boxes are expanded to the sidefaces of their respective neighboring voxels and the volume is calculated by summing up the volumes of all bounding-box adjusted voxels. Here we worked with the original resolution of the point clouds.

Wood volume estimation via cylindermodel approaches

We used two geometric-primitive-based approaches to estimate wood volumes. The first approach we tested is the one originally developed by Raumonen et al. (2013 - hereafter referred to as Raumonen et al.) and which was further developed and validated in Calders et al. (2015) and Raumonen et al. (2015). The method partitions the point cloud into small subsets based on user-defined sizes. These subsets, or surface patches, work as the smallest units, which are used to segment the point cloud of a tree into the stem and individual branches. The segmentation is based on surface growing of the patches, starting from the base of the stem and branches, and locally checking connectivity of small group of patches. The partition into patches and the segmentation are performed twice: the first partition uses large uniformly sized patches to quickly estimate the branching structure and local branch size, and based on that the second partition uses patches of a smaller and variable size to produce finer segmentation. In the next step circular cylinders are fitted into the segments. The relative length (length/ radius) of the fitted cylinders approximately equals a user given value. It is also possible to fit other geometric primitives into the subsets, e.g., cones or elliptical cylinders. However, circular cylinders are the most robust primitive to describe the tree and its structure (Akerblom et al. 2015). Non-connecting cylinders are automatically extended to form a complete model. Finally the tree parameters of interest (i.e., wood volume, branch angles, branch and trunk diameter, etc.) can be read from the cylinder model. Because the partitions into patches are random, every modeling run produces slightly different models and therefore we always made five models per input and calculated the average from these models. The important input parameters were optimized for each tree by the following simple procedure: the models were calculated with all possible parameter combinations - the minimum patch size, the maximum patch size, relative cylinder length, and outlier removal radius for cylinder fitting - and the combination that was selected was the one with the smallest standard deviation of the point-to-model distances. The point-tomodel distance (that is, the minimum of all the distances between the point and all cylinders) for automatic parameter optimization in the QSM building method relies on Hackenberg et al. (2015b). We used the following possible parameter values: minimum patch size of $5 \mathrm{~mm}$ and $10 \mathrm{~mm}$; maximum patch size: $30 \mathrm{~mm}, 40 \mathrm{~mm}, 50 \mathrm{~mm}$; relative cylinder length: $4,6,8$; relative radius for outlier removal: $2,2.5,3,3.5,4$. The algorithm runs in Matlab ${ }^{\circledast}$ (MathWorks, Natick, MA, USA) version R2015a.

The second approach we tested is by
Hackenberg et al. (2014 - hereafter abbreviated as Hackenberg et al.). This approach utilizes search spheres to follow the tree's branching structure from its root to its tips. On each sphere's surface the cross sectional areas of the underlying branch are represented by circular point structures. Circles are fitted and then transformed to enlarged spheres. The method is repeated recursively with the new detected spheres and stops when a sphere reaches a tip or a large occlusion gap. An open source software exists (Hackenberg et al. 2015a, Rusu \& Cousins 2011) with support given as a web page (http://www.simpletree.uni-frei burg.de). User and self-critics of the software's author include the support for Linux OS only and a high-dimensional space of input parameters. A free plugin for the Computree platform (http://computree.onf .fr/?lang=en) was released accounting to both critics. The main operating system of Computree is Microsoft Windows ${ }^{\oplus}$ and the method parameters are guessed internally by point cloud and tree features and are optimized user-hidden. The sphere-following method is extended with the attractor technique presented in Côté et al. (2011, 2012) to allow the method to handle large gaps in the point clouds. The plugin is currently in an early alpha version, but could produce the results presented here, as well as on other available clouds. The full plugin will be presented in detail in a future publication as soon as it reaches a stable state. All 24 trees could be modelled in a total of 163 seconds (Intel(R) Xeon(R) CPU E5-1650 v3).

Statistical data analysis of the volumetric results was performed with $\mathrm{R}$ ( $\mathrm{R}$ Core Team 2015).

\section{Results}

Wood volume estimates from the point clouds were successfully derived for all 24 trees with all three methods (Tab. 1). In general, all the three methods agreed well when compared to the xylometric reference measurements (Fig. 2). The voxel-based method gave the best results overall $\left(r^{2}=0.98-\right.$ Fig. 2) with an average underestimation of less than $1 \%$ (MAE 9.8\%). The
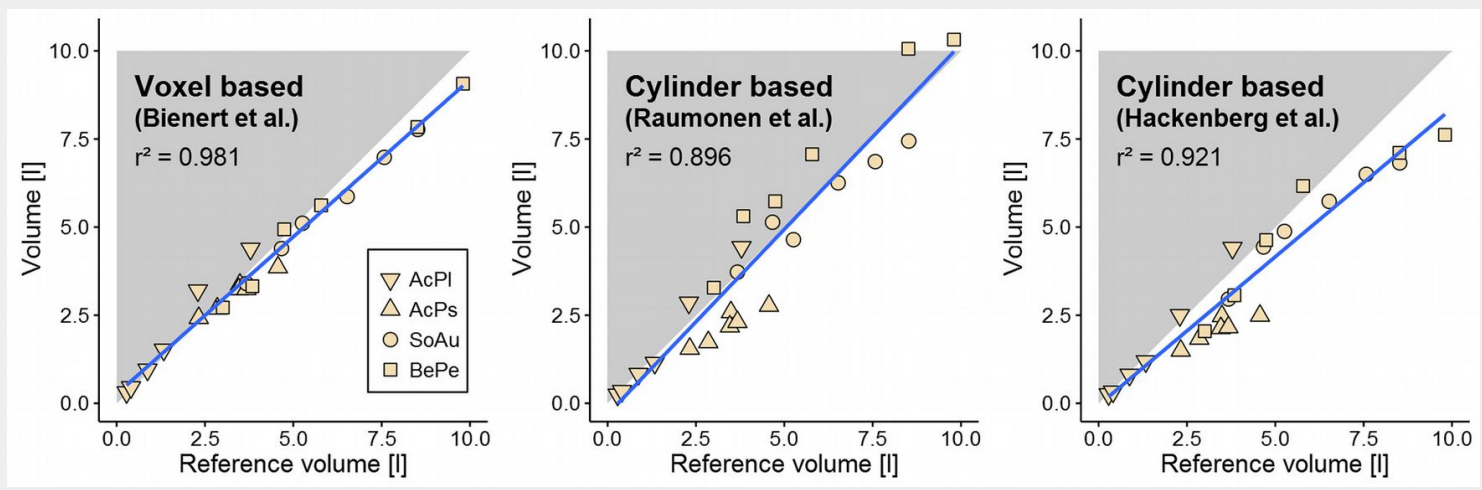

Fig. 2 - Regression plots and $r^{2}$ values between xylometric reference measurements and point cloud method based estimates. Methods: (left) Bienert et al. (2014); (middle) Raumonen et al. (2013); (right) Hackenberg et al. (2014). Blue line

shows linear fit between reference measurements and estimate. The 1:1 line is visualized by the diagonal borderline of the gray triangle. Different tree species are indicated by different point types. Species abbreviations: (AcPI) Acer platanoides; (AcPs) Acer pseudoplatanus; (SoAu) Sorbus aucuparia; (BePe) Betula pendula. 
cylinder-primitive based method of Raumonen et al. showed a similar level of accuracy, with an underestimation of less than $6 \%$, but showed a higher variance (MAE $\left.19.3 \%, r^{2}=0.90\right)$. The method of Hackenberg et al. performed less well because it tends to underestimate the volumes by $17.3 \%$ (MAE 19.9\%, $r^{2}=0.92$ ). When comparing the absolute volume (sum) of all trees the method by Raumonen et al. was closest to the reference measurements (Tab. 1).

We found a significant variation in the error of the estimates between tree species across all methods (Tab. 2). The highest mean error over all three methods was obtained for an Acer pseudoplatanus tree (No. 12 in Tab. 1). The wood volume of this tree species was generally underestimated by all methods. The volumes derived for Betula pendula (species with a complex structure in our study) showed the strongest variations across methods. The esti-
Tab. 2 - Effect of diameter at breast height (DBH), tree height (TH) and tree species on the error of the volume estimates using different methods. Significance of DBH and $\mathrm{TH}$ was tested using simple linear regression. Significance of tree species was tested by one-way ANOVA. $\left({ }^{*}\right)$ : $p<0.05 ;\left({ }^{* *}\right)$ : $p<0.01 ;(* * *)$ : $p<0.001 ;(n s)$ : not significant.

\begin{tabular}{lccc}
\hline \multirow{2}{*}{ Parameter } & \multicolumn{3}{c}{ Effect of error on volumetric estimate } \\
\cline { 2 - 4 } & \multicolumn{1}{c}{ Bienert et al. } & Raumonen et al. & Hackenberg et al. \\
\hline DBH & ${ }^{*}\left(\mathrm{~F}_{1.22}=5.3\right)$ & $\mathrm{ns}$ & $\mathrm{ns}$ \\
TH & ${ }^{* * *}\left(\mathrm{~F}_{1.22}=18.5\right)$ & $\mathrm{ns}$ & $\mathrm{ns}$ \\
Species & ${ }^{* * *}\left(\mathrm{~F}_{3,20}=14.7\right)$ & ${ }^{* * *}\left(\mathrm{~F}_{3.20}=22.5\right)$ & ${ }^{* * *}\left(\mathrm{~F}_{3.20}=11.0\right)$ \\
\hline
\end{tabular}

mates obtained for Sorbus aucuparia best 0.001$)$ and TH $\left(F_{1.22}=5.3, p<0.05\right)$ had a sigagreed with the reference measurements nificant effect on the error of the estiand showed the lowest variations (Fig. 3). mates.

Comparing $\mathrm{DBH}$ and $\mathrm{TH}$ with the differences of the reference volumes did not reveal significant trends for the cylinderbased methods (Fig. 4). Only using the Discussion

All three methods can be used to compute wood volume estimates for young voxel-based method DBH $\left(\mathrm{F}_{1.22}=18.4, \mathrm{p}<\right.$ trees from TLS-derived point clouds. The
Fig. 3-(Top): Wood volume estimates for 24 trees of four tree species from three different methods. Different methods are indicated by different point types and colors. Tree volumes are plotted on a logarithmic scale for easier comparison between small and larger volumes. Trees are sorted by species and increasing diameter at breast height (DBH). Species abbreviations: (AcPI) Acer platanoides; (AcPs) Acer pseudoplatanus; (SoAu) Sorbus aucuparia; (BePe) Betula pendula. (Bottom): Percentage difference of point cloud estimates to xylometric reference volume. $\pm 25 \%$ value is plotted as dashed line for better visual interpretation. Vertical gray lines are plotted to differentiate between sets of different species.

Fig. 4 - Plot of diameter at breast height (DBH) and tree height $(\mathrm{TH})$ versus the observed differences of all three methods to the reference volumes. Different tree species are indicated by different point types. Methods are indicated by color: red refers to Bienert et al. (2014), blue refers to Raumonen et al. (2013), green refers to Hackenberg et al. (2014). Species abbreviations: (AcPl) Acer platanoides; (AcPs) Acer pseudoplatanus; (SoAu) Sorbus aucuparia; (BePe) Betula pendula.
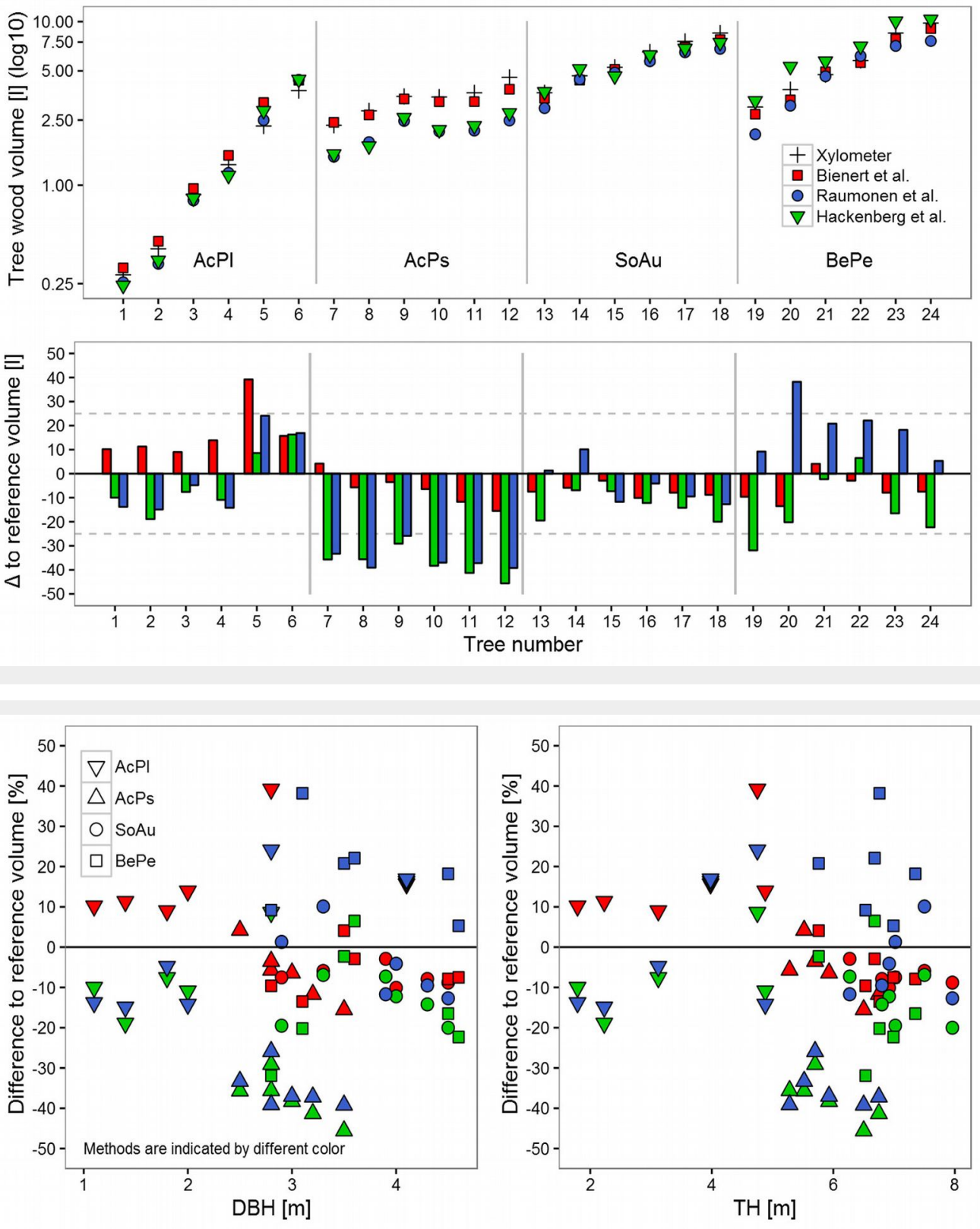
Tab. 3 - Potential group of structural tree (species) parameters for the description and development of species specific parameters settings of pointcloud based methods for wood volume estimation. Diameter at breast height $(\mathrm{DBH})$, tree height $(\mathrm{TH})$, ground diameter (GD).

\begin{tabular}{l} 
Tree (species) parameters \\
\hline Height, DBH (or GD) Height/DBH (or GD) \\
ratio \\
Number of branches \\
Minimum branch radius \\
Mean branch length/radius ratio \\
Mean branch angle \\
Maximum branch order \\
Stem/branch radius ratio \\
\hline
\end{tabular}

achievable accuracies are sufficiently high to grant reliable results in wide range of ecological and forestry applications. Cur rently, all the three tested methods rely on user input. In particular the two QSM methods require to set multiple parameters that can have a significant effect on the estimate, e.g., minimum radii. The complex setting of these parameters should be simplified to allow for the use of these methods without the need for advanced knowledge in point cloud modeling. For a better comparison of the tested methods we used identical parameter settings (see above) in each method for all trees in the sample.

The observed errors in the estimates can be mainly related to structural differences among tree species rather than to the methods themselves. Indeed, tree trunks hold most of the wood volume and can be extracted with high accuracies, while errors in volume estimation were mainly attributed to the branches (Hackenberg et al. 2015b, Hess et al. 2015). Whereas branches are detected generally well, visual inspection of the resulting cylinder models using QSM methods showed that the observed underestimation, as well as overestimation, of the cylinder-primitive approaches was mainly explained by over- or undersized cylinder diameters at thin branches. The bounding-box adjustment of the tested voxel-based method did not have this problem and showed the lowest overall error. For instance, Betula pendula typically consists of a large number of long thin branches, while Sorbus aucuparia is characterized by fewer, shorter and thicker branches. The latter species is less prone to error (see Tab. 2 and Fig. 3) due to a larger number of laser points that actually hit the branches (depending on the scan resolution) and a lower number of branches that may have an incorrect cylinder fit.

In few cases branches of higher order showed a larger cylinder diameter than branches of lower order. Actually, for most tree individuals this will not be true. Both cylinder-based methods use a threshold for the minimum size of cylinder radii at branches (2.5 $\mathrm{mm}$ in our case). If radii are smaller than this value they are adjusted (enlarged) to this threshold, leading to an overestimation especially at very thin branches. The methods of Raumonen et al. and Hackenberg et al. gave similar results except for Betula pendula. The large number of branches in this species, especially second order branches, yielded a larger overall error even though the error of the fitted cylinder radii can be small. Contrastingly, the large underestimation observed for Acer pseudoplatanus (36\% on average) using the cylinder-based methods could not be related to any specific tree parameter. A possible explanation could be that the trunk and branches are not of cylindrical shape or that the ratio between cylinder length and radius is not suited for the samples of this tree species. However, for Sorbus aucuparia we did not observe such a large underestimation, despite its higher structural complexity. Another possibility are registration errors or noise in the point clouds.

The fact that the tree species had a significant influence on the error of the estimate using all methods (Tab. 2) calls for sets of species-specific parameters, especially for the cylinder-based methods. Currently such parameter sets do not exist and more research for a range of tree species is required. In the practice, it will not always be possible to know the species of a tree that is represented in the point cloud; however, even in such cases species-specific parameter sets would be useful. By analyzing the QSM information for a set of reference species, groups of parameters that describe that species, e.g., using support vector machines or linear discriminant analysis, may be developed (see Tab. 3). This would help identifying the species identity for trees of unknown species in the point cloud in large scale studies on natural forests. In particular, parameters accounting for the structural characteristics of a species or a group of species are desirable. One suggestion is to set the minimum branch diameters based on the branch order level and the type of species. To this purpose, iterative approaches could be applied which optimize the method parameters and identify the species first, before applying this information in consecutive runs.

The observed influence of DBH and TH on the error using the voxel-based method (Tab. 2, Fig. 4) indicates that it is not feasible to apply a constant voxel size for all point clouds in the case of large variations in DBH and branch diameter. In our case a voxel size of $7 \mathrm{~mm}$ was suitable for all tree samples (young understorey trees, $\mathrm{TH}<8$ $\mathrm{m})$, but this may not fit when analyzing larger trees and sample sizes. When the wood volume at the plot level is required and larger trees are included in the sample, this has to be considered and carefully adapted. In this regard, cylinder-based methods adapt much better to variations in diameters and tree height, though they yield larger errors of the estimates. The voxel-based method of Bienert et al. (2014) currently does not calculate the branching structure. To improve that method a treeskeletonization routine could be included to allow for local adjustments of the voxel size, together with the bounding-box adjustment routine, at branches of higher order. An initial voxel size estimate based on $\mathrm{DBH}$ and TH should be used to set the optimal voxel size. DBH and TH can be extracted relatively straight forward (Dassot et al. 2011) and ground truth sampling is not required.

\section{Conclusions}

All three methods compared in this study proved to be appropriate (in terms of their accuracy) to derive wood volumes of young deciduous trees from TLS point clouds. This is promising for their use in wider ecological applications such as treegrowth analysis (Sheppard et al. 2016) or long-term forest biodiversity experiments were non-destructive measurements are essential ( $\mathrm{Li}$ et al. 2014). The use of voxelbased methods should be favored when only the total tree volume has to be estimated, as these methods are easy to use and yield robust results. However, the geometric-primitive (QSM) based approaches currently offer more output parameters (e.g., branching order, branch angles and radii) in a very small file size. This additional information is highly valuable in terms of finding optimized method parameters that account for species-specific differences in the structural complexity and branch sizes. Currently, such parameter sets do not exist and further research with a larger sample is required. Although all the three tested methods include some optimization or adjustment routines, their initial input parameters were not altered with regards to the tree species - which is highly related to the error of the estimate. Therefore, careful consideration is needed to select the best input parameters for each method, as initial information on the trees and their respective point clouds is essential. Using species-specific parameter sets and combining the advantages of voxel-based and cylinder-based methods the estimation of highly accurate wood volume estimates from point clouds of trees is certainly possible.

Advancements of the methods analyzed in this study can also help to provide improved estimates of the related tree biomass, which is the goal of many studies. Allometric regression models including TLS-based information can be provided with more accurate information compared to simple point cloud metrics (Seidel et al. 2011b). Nonetheless, wood densities are currently still required to convert the volumes into an accurate estimate of biomass.

\section{Acknowledgements}

MK performed the data analysis and 
wrote the manuscript. $\mathrm{CH}$ and $\mathrm{GvO}$ conceived and designed the field experiments. $\mathrm{CH}$ carried out the field work. $\mathrm{CH}, \mathrm{PR}, \mathrm{AB}$, $\mathrm{JH}$ and $\mathrm{AF}$ analysed the data and contributed to the manuscript. $\mathrm{HGM}, \mathrm{WH}, \mathrm{AF}$ and $\mathrm{GvO}$ contributed to the interpretation of the results and preparation of the manuscript.

We thank Moritz-Christian von Oheimb for support in obtaining the experimental data from Enzen forest. Carsten Hess is very grateful to the program and scholarship of the Leuphana Graduate School "DIABOLO - Distributed, Integrated and Harmonised Forest Information for Bioeconomy Outlooks". This project has received funding from the European Union's Horizon 2020 research and innovation programme under the grant agreement no. 633464 .

\section{References}

Aiteanu F, Klein R (2014). Hybrid tree reconstruction from inhomogeneous point clouds. The Visual Computer 30: 763-771. - doi: 10.1007/s003 71-014-0977-7

Akerblom $M$, Raumonen $P$, Kaasalainen $M$, Casella E (2015). Analysis of geometric primitives in quantitative structure models of tree stems. Remote Sensing 7: 4581-4603. - doi: 10.3390/rs70404581

Ashcroft MB, Gollan JR, Ramp D (2014). Creating vegetation density profiles for a diverse range of ecological habitats using terrestrial laser scanning. Methods in Ecology and Evolution 5: 263-272. - doi: 10.1111/2041-210X.12157

Bayer D, Seifert S, Pretzsch H (2013). Structural crown properties of Norway spruce (Picea abies [L.] Karst.) and European beech (Fagus sylvatica [L.]) in mixed versus pure stands revealed by terrestrial laser scanning. Trees 27 : 1035-1047. - doi: 10.1007/s00468-013-0854-4 Bienert A, Hess C, Maas HG, Von Oheimb G (2014). A voxel-based technique to estimate the volume of trees from terrestrial laser scanner data. International Archives of Photogrammetry and Remote Sensing XL- 5: 101-106. - doi: 10.5194/isprsarchives-XL-5-101-2014

Bruelheide $\mathrm{H}$, Nadrowski K, Assmann T, Bauhus J, Both S, Buscot F, Chen XY, Ding B, Durka W, Erfmeier A, Gutknecht JLM, Guo D, Guo LD, Härdtle W, He JS, Klein AM, Kühn P, Liang Y, Liu $X$, Michalski S, Niklaus PA, Pei K, Scherer-Lorenzen $M$, Scholten T, Schuldt A, Seidler $G$, Trogisch S, Von Oheimb G, Welk E, Wirth C, Wubet $\mathrm{T}$, Yang $\mathrm{X}, \mathrm{Yu} \mathrm{M}$, Zhang $\mathrm{S}$, Zhou $\mathrm{H}$, Fischer $\mathrm{M}$, Ma K, Schmid B (2014). Designing forest biodiversity experiments: general considerations illustrated by a new large experiment in subtropical China. Methods in Ecology and Evolution 5: 74-89. - doi: 10.1111/2041-210X.12126

Bucksch A, Lindenbergh R (2008). CAMPINO - A skeletonization method for point cloud processing. ISPRS Journal of Photogrammetry and Remote Sensing 63: 115-127. - doi: 10.1016/j.isprs jprs.2007.10.004

Bucksch A, Lindenbergh R, Menenti M (2010). SkelTre. The Visual Computer 26: 1283-1300. doi: 10.1007/s00371-010-0520-4

Calders K, Newnham G, Burt A, Murphy S, Raumonen $P$, Herold $M$, Culvenor $D$, Avitabile $V$,
Disney M, Armston J, Kaasalainen M (2015). Nondestructive estimates of above-ground biomass using terrestrial laser scanning. Methods Ecology and Evolution 6: 198-208. - doi: 10.1111/ 2041-210X.12301

Côté JF, Fournier RA, Egli R (2011). An architectural model of trees to estimate forest structural attributes using terrestrial LiDAR. Environmental Modelling and Software 26: 761-777. doi: 10.1016/j.envsoft.2010.12.008

Côté JF, Fournier RA, Frazer GW, Niemann KO (2012). A fine-scale architectural model of trees to enhance LiDAR-derived measurements of forest canopy structure. Agricultural and Forest Meteorology 166: 72-85. - doi: 10.1016/j.agrfor met.2012.06.007

Dassot M, Constant T, Fournier M (2011). The use of terrestrial LiDAR technology in forest science: application fields, benefits and challenges. Annals of Forest Science 68: 959-974. doi: 10.1007/s13595-011-0102-2

Delagrange S, Jauvin C, Rochon P (2014). Pypetree: A tool for reconstructing tree perennial tissues from point clouds. Sensors 14: 42714289. - doi: 10.3390/\$140304271

Dijkstra EW (1959). A note on two problems in connection with graphs. Numerische Mathematik 1: 269-271. - doi: 10.1007/BF01386390

EDF (2014). CloudCompare (version 2.5) [GPL software]. EDF R\&D, Telecom ParisTech, Web site. [online] URL: http://www.cloudcompare. org

FARO Technologies (2012). FARO Scene 5.0 User's Manual. FARO Technologies Inc., Lake Mary, FL, USA. [online] URL: http://www.faro. com/en-us/products/faro-software/scene/down loads

Forrester D, Pretzsch H (2015). Tamm review: on the strength of evidence when comparing ecosystem functions of mixtures with monocultures. Forest Ecology and Management 356: 4153. - doi: 10.1016/j.foreco.2015.08.016

Gorte B, Pfeifer N (2004). Structuring laserscanned trees using $3 \mathrm{D}$ mathematical morphology. International Archives of Photogrammetry and Remote Sensing 35 (B5): 929-933. - http:// citeseerx.ist.psu.edu/viewdoc/download?doi= 10.1.1.438.1610

Grissino-Mayer H (2003). A manual and tutorial for the proper use of an increment borer. TreeRing Research 59: 63-79. [online] URL: http:// arizona.openrepository.com/arizona/handle/101 50/262572

Hackenberg J, Morhart C, Sheppard J, Spiecker H, Disney M (2014). Highly accurate tree models derived from terrestrial laser scan data: a method description. Forests 5: 1069-1105. - doi: 10.3390/f5051069

Hackenberg J, Spiecker H, Calders K, Disney M, Raumonen P (2015a). SimpleTree - an efficient open source tool to build tree models from TLS Clouds. Forests 6: 4245-4294. - doi: 10.3390/f611 4245

Hackenberg J, Wassenberg $M$, Spiecker $H$, Sun D (2015b). Non destructive method for biomass prediction combining TLS derived tree volume and wood density. Forests 6: 1274-1300. - doi: 10.3390/f6041274

Henning JG, Radtke PJ (2006). Ground-based laser imaging for assessing three-dimensional forest canopy structure. Photogrammetric En- gineering and Remote Sensing 72: 1349-1358. doi: 10.14358/PERS.72.12.1349

Hese S, Lucht W, Schmullius C, Barnsley M, Dubayah R, Knorr D, Neumann K, Riedel T, Schroter K (2005). Global biomass mapping for an improved understanding of the $\mathrm{CO}_{2}$ balance the Earth observation mission Carbon-3D. Remote Sensing of the Environment 94: 94104. - doi: 10.1016/j.rse.2004.09.006

Hess C, Bienert A, Härdtle W, Von Oheimb G (2015). Do tree crown structures influence the accuracy of wood volume estimates by terrestrial LiDAR? Forests 6: 3847-3867. - doi: 10.3390/ f6113847

Hosoi F, Nakai Y, Omasa K (2013). Voxel tree modeling for estimating leaf area density and woody material volume using 3-D LIDAR data. ISPRS Annals of Photogrammetry, Remote Sensing and Spatial Information Sciences II5/W2: 115-120. - doi: 10.5194/isprsannals-II-5-W2115-2013

Jayaratna S (2009). Baumrekonstruktion aus 3DPunktwolken [Tree reconstruction from 3D point clouds]. Diploma thesis, University of Bonn, Bonn, Germany, pp. 73. [in German] [online] URL: http://pdfs.semanticscholar.org/ 9a9c/c198cf57d307ef8909388922cf43ea3500c8 .pdf

Lamprecht S, Stoffels J, Udelhoven T (2015). VecTree - Concepts for 3D modelling of deciduous trees from terrestrial Lidar. PhotogrammetrieFernerkundung-Geoinformation 3: 241-255. doi: $10.1127 / \mathrm{pfg} / 2015 / 0266$

Li Y, Hess C, Von Wehrden H, Härdtle W, Von Oheimb G (2014). Assessing tree dendrometrics in young regenerating plantations using terrestrial laser scanning. Annals of Forest Science 71: 453-462. - doi: 10.1007/s13595-014-0358-4

Liang X, Kankare V, Yu X, Hyyppa J, Holopainen M (2014). Automated stem curve measurement using terrestrial laser scanning. IEEE Transactions on Geosciences and Remote Sensing 52: 1739-1748. - doi: 10.1109/TGRS.2013.2253783

Livny Y, Yan F, Olson M, Chen B, Zhang H, ElSana J (2010). Automatic reconstruction of tree skeletal structures from point clouds. ACM Transactions on Graphics 29: 151. [online] URL: http://dl.acm.org/citation.cfm?id=1866177

Maas HG, Bienert A, Scheller S, Keane E (2008). Automatic forest inventory parameter determination from terrestrial laser scanner data. International Journal of Remote Sensing 29: 15791593. - doi: 10.1080/01431160701736406

Martin-Ducup O, Schneider R, Fournier RA (2016). Response of sugar maple (Acer saccharum Marsh.) tree crown structure to competition in pure versus mixed stands. Forest Ecology and Management 374: 20-32. - doi: 10.1016/ j.foreco.2016.04.047

Mikita T, Janata P, Surový P (2016). Forest stand inventory based on combined aerial and terrestrial close-range photogrammetry. Forests 7 (8): 165. - doi: 10.339o/f7080165

Muukkonen P (2007). Generalized allometric volume and biomass equations for some tree species in Europe. European Journal of Forest Research 126: 157-166. - doi: 10.1007/s10342-0070168-4

Nölke N, Fehrmann L, I Nengah SJ, Tiryana T, Seidel D, Kleinn C (2014). On the geometry and allometry of big-buttressed trees - a challenge 
for forest monitoring: new insights from 3Dmodeling with terrestrial laser scanning. iForest 8: 574-581. - doi: 10.3832/ifor1449-007

Oggier T, Lehmann M, Kaufmann R, Schweizer $M$, Richter $M$, Metzler $P$, Lang $G$, Lustenberger F, Blanc N (2003). An all-solid-state optical range camera for $3 \mathrm{D}$ real-time imaging with subcentimeter depth resolution (SwissRang$\left(\mathrm{er}^{\mathrm{TM}}\right)$. SPIE Proceedings Series 5249 (65): 534545. - doi: 10.1117/12.513307

Picard N, Saint-Andre L, Henry M (2012). Manual for building tree volume and biomass allometric equations: from field measurement to prediction. Food and Agriculture Organization of the United Nations (FAO): Rome, Italy; Centre de Coopération Internationale en Recherche Agronomique pour le Développement (CIRAD), Montpellier, France, pp. 215. [online] URL: http://www.fao.org/docrep/018/i3058e/i3058e. pdf

Pretzsch H (2010). Forest dynamics, growth and yield. Springer, Berlin, Heidelberg, Germany, pp. 664.

Pretzsch H (2014). Canopy space filling and tree crown morphology in mixed-species stands compared with monocultures. Forest Ecology and Management 327: 251-264. - doi: 10.1016/j. foreco.2014.04.027

R Core Team (2015). R: a language and environment for statistical computing. R Foundation for Statistical Computing, Vienna Austria. URL. [online] URL: http://www.R-project.org/
Raumonen P, Kaasalainen M, Akerblom M, Kaasalainen $\mathrm{S}$, Kaartinen $\mathrm{H}$, Vastaranta $\mathrm{M}$, Holopainen M, Disney M, Lewis P (2013). Fast automatic precision tree models from terrestrial laser scanner data. Remote Sensing 5: 491-520. - doi: 10.3390/rs5020491

Raumonen P, Casella E, Calders K, Murphy S, Akerblom M, Kaasalainen M (2015). Massivescale tree modelling from TLS data. ISPRS Annals of Photogrammetry, Remote Sensing and Spatial Information Sciences II-3/W4: 189196. - doi: 10.5194/isprsannals-II-3-W4-189-2015 Rusu RB, Cousins S (2011). 3D is here: Point Cloud Library $(P C L)$. In. Proceedings of the "IEEE International Conference on Robotics and Automation (ICRA)". Shangai (China) 9-13 May 2011. IEEE Xplore Digital Library, pp. 1-4. - doi: 10.1109/ICRA.2011.5980567

Scherer-Lorenzen M, Schulze ED, Don A, Schumacher J, Weller E (2007). Exploring the functional significance of forest diversity: a new long-term experiment with temperate tree species (BIOTREE). Perspectives in Plant Ecology, Evolution and Systematics 9: 53-70. - doi: 10.101 6/j.ppees.2007.08.002

Seidel D, Fleck S, Leuschner C, Hammett T (2011a). Review of ground-based methods to measure the distribution of biomass in forest canopies. Annals of Forest Science 68: 225-244. - doi: 10.1007/s13595-011-0040-z

Seidel D, Beyer F, Hertel D, Fleck S, Leuschner C (2011b). 3D-laser scanning: a non-destructive method for studying above-ground biomass and growth of juvenile trees. Agricultural and Forest Meteorology 151: 1305-1311. - doi: 10.1016/ j.agrformet.2011.05.013

Seidel D, Schall P, Gille M, Ammer C (2015). Relationship between tree growth and physical dimensions of Fagus sylvatica crowns assessed from terrestrial laser scanning. iForest 8: 735742. - doi: 10.3832/ifor1566-008

Sheppard J, Morhart C, Hackenberg J, Spiecker $\mathrm{H}$ (2016). Terrestrial laser scanning as a tool for assessing tree growth. iForest 10 (1): 172-179. doi: 10.3832/ifor2138-009

Thies M, Pfeifer N, Winterhalder D, Gorte B (2004). Three-dimensional reconstruction of stems for assessment of taper, sweep and lean based on laser scanning of standing trees. Scandinavian Journal of Forest Research 19: 571-581. - doi: 10.1080/02827580410019562

Wang Z, Zhang L, Fang T, Mathiopoulos PT, Qu H, Chen D, Wang Y (2014). A structure-aware global optimization method for reconstructing 3-D tree models from terrestrial laser scanning data. IEEE Transactions on Geoscience and Remote Sensing 52: 5653-5669. - doi: 10.1109/ TGRS.2013.2291815

Xu H, Gossett N, Chen B (2007). Knowledge and heuristic-based modeling of laser-scanned trees. ACM Transactions on Graphics (TOG) 26: 19. - doi: $10.1145 / 1289603.1289610$ 